\title{
Autoimmune Lymphoproliferative Syndrome-Associated Lymphoma
}

National Cancer Institute

\section{Source}

National Cancer Institute. Autoimmune Lymphoproliferative Syndrome-Associated Lymphoma. NCl Thesaurus. Code C39578.

A lymphoma that arises in the context of autoimmune lymphoproliferative syndrome. 